\title{
In Vitro Ovine Embryo Production: the Study of Seasonal and Oocyte Recovery Method Effects
}

\author{
Navid Dadashpour Davachi ${ }^{1}$; Ahmad Zare Shahneh ${ }^{1,} ;$ Hamid Kohram $^{1,2}$; Mahdi Zhandi ${ }^{1}$; \\ Saeed Dashti ${ }^{1}$; Helia Shamsi ${ }^{1}$, Razieh Moghadam ${ }^{3}$ \\ ${ }^{1}$ Department of Animal Science, Faculty College of Agriculture and Natural Resources, University of Tehran, Karaj, IR Iran \\ ${ }^{2}$ Department of Clinical Sciences, Faculty of Veterinary Medicine, Shahid Chamran University, Ahvaz, IR Iran \\ ${ }^{3}$ Kowsar Corporation, Tehran, IR Iran \\ ${ }^{*}$ Corresponding Author: Ahmad Zare Shahneh, Department of Animal Science, Faculty College of Agriculture and Natural Resources, University of Tehran, Karaj, IR Iran. Tel: +98- \\ 9123446217, Fax: +98-2612246752, E-mail: navid.d60@gmail.com; azareh@ut.ac.ir
}

Received: August 8, 2014; Revised: August 24, 2014; Accepted: August 29, 2014

\begin{abstract}
Background: To current knowledge, different oocyte's recovery method and various seasons have profound impact on in vitro embryo production(IVEP).

Objectives: The aim of this study was to define an efficient recovery method for oocytes harvesting from slaughterhouse material in different seasons, and their effects on IVEP yield.

Materials and Methods: Ovaries from slaughtered ewes in breeding season (BS) and non-breeding season (NBS) were collected from a local abattoir. The oocytes were recovered through aspiration, centrifugation (ORC), puncture and slicing, and categorized into three classes (I, oocytes with more than three layers of cumulus cells; II, less than three layers with damaged cumulus cells; III, denuded oocytes). After cultivation in TCM199 for 24 hours, matured oocytes were subjected to in vitro fertilization (IVF) and in vitro culture (IVC). The oocyte recovery using ORC in BS and NBS was significantly higher $(\mathrm{P}<0.05)$ compared with other recovery methods.

Results: No significant dissimilarities in the proportion of oocytes reaching M-II stage were recorded when using different oocyte recovery methods in different seasons. Aspiration resulted in lower $(\mathrm{P}<0.05)$ proportion of class I (BS, $60.0 \pm 2.1 ; \mathrm{NBS}$, 51.1 \pm 2.1$)$ compared to ORC (BS, 82.0 \pm 1.2 ; NBS, $70.0 \pm 1.2$ ), slicing (BS, $80.0 \pm 2.1$; NBS, $71.0 \pm 1.4$ ) and puncture (BS, $80.0 \pm 1.5 ; \mathrm{NBS}, 72.0 \pm 2.0$ ). Monospermy and blastocyst development rates were significantly higher using ORC than other recovery techniques in both BS and NBS. More oocytes with high quality, greater blastocyst development and oocyte recovery rates were achieved in BS.

Conclusions: The results revealed that oocytes harvesting technique and season are effective in the rate of cleavage and blastocysts' development, and suggest that despite same meiotic resumption rate in all treatments, it would be better to use ORC.
\end{abstract}

Keywords:In Vitro Oocyte Maturation Techniques; Fertilization in Vitro; Embryo Production; Sheep; Oocytes

\section{Background}

In ovine, only a limited number of mature oocytes can be collected via superovulation and subsequent ovum pick up (OPU) procedure. Ovaries obtained from slaughtered animals are the most abundant and inexpensive sources of oocytes for in vitro embryo production (IVEP) (1-3). "Reproductive seasonality in the ewe is characterized by changes at behavioral, endocrine and ovulatory levels, in an absolute fashion, giving rise to an annual alternation between two distinct periods; a breeding season, characterized by the succession at regular intervals (mean of 17 days) of estrous behavior and ovulation, if a pregnancy does not develop, and an anestrous season characterized by the cessation of sexual activity" (1). Considering that ovine is a seasonal breeder species and a great influence of different seasons on their hormonal and systemic changes, it would be reasonable to consider a combination of seasonal effects with other primary steps as the most important elements may affect the success rate of IVEP (4).
Several factors influence the IVEP and the optimization of in vitro techniques could improve the IVEP efficiency (4). Higher percentages of blastocysts are obtained via in vivo maturation of oocytes compare to in vitro maturation (IVM). This kind of evidence suggests that in vitro milieu is not sufficient for supporting development and early embryo competence (5). Due to the significant impact of the seasons on ovine reproductive cycle, it is not uncommon for IVM-IVF systems to endure some deficiencies in non-breeding seasons (6). Thus the IVEP yield may increase by optimizing the IVM system (6). The ovarian status and different seasons have a great influence on ovine embryo production. The results of a study conducted by Bartlewski et al. (7) have previously showed that the in vitro developmental competence of ovine oocytes was influenced by hormonal treatment and the endocrine status of the donor. On the other hand, Ramsingh et al. (8) reported that ovarian biometrics have a great influ-

Copyright ( ) 2014, Iranian Red Crescent Medical Journal; Published by Kowsar. This is an open-access article distributed under the terms of the Creative Commons Attribution-NonCommercial 4.0 International License (http://creativecommons.org/licenses/by-nc/4.0/) which permits copy and redistribute the material just in noncommercial usages, provided the original work is properly cited. 
ence on oocyte grading and recovery rate, and have great fluctuations in goat. The ovarian biometric variations are associated to the breeding, seasonal and nutritional status. To current knowledge, the seasonal effects on IVEP have not been appropriately studied.

Along with various seasons, one of the most important factors that can influence the success of the IVEP is the efficient recovery of the cumulus-oocyte complexes (COC's) (9). A large number of good-quality oocytes are needed for prosperous embryo production, as approximately only $30 \%$ of oocytes may develop into blastocysts (10). Aspiration, slicing and puncture of whole ovarian surface had served as the conventional methods for oocytes harvesting. Each of which have their advantages and disadvantages (2). In this study, a new oocyte harvesting technique (oocyte recovery via centrifugation $=\mathrm{ORC}$ ) that has recently been established by Dadashpour Davachi (11) along with other conventional harvesting methods were used for oocyte's recovery.

In the production of IVM-IVF embryos, the number of oocytes recovered per ovary and the oocyte's competence are of important consideration. Demonstrating the most efficient oocytes harvesting method and seasonal effects on oocyte developmental competence and embryo yield is highly desirable. In the previous study conducted by Dadashpour Davachi (11) the number of recovered oocytes and meiotic competence rate were considered as possible indicators for evaluating ORC technique. While one of the endpoints for possible evaluations of any modifications in assisted reproductive technology (ART), would be the early embryonic developmental competence.

\section{Objectives}

This study was aimed to assess the possible influence of oocyte harvesting technique in different seasons on oocyte developmental competence and subsequent IVF and IVC efficiency, using sheep as a model.

\section{Materials and Methods}

All media used for IVM and IVF were incubated at $38.5^{\circ} \mathrm{C}$ and $5 \% \mathrm{CO} 2$ with maximum humidity for 2 hours prior to use. Two sets of experiments for this study were done respectively in breeding and non-breeding seasons.

Ovine ovaries $(n=1635)$ were collected from Zandi ewes which were between 1.5-3.5 years old during breeding (September to November) and non-breeding seasons (June to August) from a local abattoir in Karaj, Iran $\left(35^{\circ} 43^{\prime} 40^{\prime \prime} \mathrm{N}-51^{\circ} 1^{\prime} 7^{\prime \prime} \mathrm{E}\right)$. Ovaries were placed in an insulated container with physiological saline solution $(0.9 \% \mathrm{NaCl})$ and penicillin/streptomycin $(50 \mathrm{IU} / \mathrm{mL})$, at $37^{\circ} \mathrm{C}$. The ovaries were transported to the laboratory within 1 hour. All the superfluous tissue and bursa were removed from ovaries surface. Each ovary was subjected to three washing in Dulbecco phosphate buffer solution (DPBS) and two washing in oocyte harvesting medium at $37^{\circ} \mathrm{C}$ (DPBS +4 $\mathrm{mg} / \mathrm{mL}, \mathrm{BSA}+50 \mathrm{IU} / \mathrm{mL}$ penicillin), prior to processing
(12). All chemicals were purchased from Sigma (Germany), unless otherwise indicated.

\subsection{Oocyte Recovery and in Vitro Maturation}

Each ovary was individually handled, and oocytes were recovered by one of the following:

\subsubsection{Methods}

1) Ovarian puncture: in this technique, 18 gauge hypodermic needles were used to puncture the ovarian surface

2) Aspiration technique: oocytes were recovered using an aspiration pump (flow rate $10 \mathrm{~mL} \mathrm{H2O} / \mathrm{min}$ ) and a $20 \mathrm{G}$ needle was attached to the apparatus

3) Slicing: the whole ovarian surface was incised by a sterile scalpel blade

4) Oocyte recovery via ORC as described by Dadashpour Davachi et al. (11). Briefly, ORC technique consisted of several steps; the first step was the incision of the entire surface of each ovary and then the ovaries were placed into modified Falcon tubes (MFT's). The MFT's were filled with $3 \mathrm{~mL}$ of a pre-incubated oocyte washing medium and centrifuged at $750 \times \mathrm{g}$ for 3 minutes. During oocyte's recovery via puncture and slicing techniques, the ovary was kept completely submerged in a medium into a $35 \mathrm{~mm}$ petridish. When harvesting the oocytes by aspiration only the visible follicles were aspirated (2). Prior to applying ORC technique, modified Falcon tubes were prepared as described by Dadashpour Davachi et al. (11).

The recovered oocytes via each of the methods were divided into three classes (classes I to III-with more than 5, 3-4 and 1-2 cumulus cell layers, respectively) and separately cultured (9).

Groups of 10 COCs were added to $50 \mu \mathrm{L}$ droplets of maturation medium consisting of TCM-199 with Earle's salts and bicarbonate supplemented with $10 \%$ heat treated FCS, $0.5 \mathrm{pg} / \mathrm{mL}$ FSH, $5 \mathrm{ug} / \mathrm{mL}$ gentamicin. The droplets, covered with mineral oil, were preincubated under maturation conditions for a minimum of $2 \mathrm{~h}\left(38.5^{\circ} \mathrm{C}, 5 \% \mathrm{CO} 2\right.$, and $95 \%$ air atmosphere with maximum humidity) (13).

\subsection{Evaluation of Nuclear Stage of Meiosis}

In vitro-matured oocytes were fixed in acetic acid and ethanol (ratio 1:3) for at least $48 \mathrm{~h}$. The COCs were subsequently stained with aceto-orcein (1\% in $45 \%$ acetic acid solution) and assessed for the nuclear stage of meiosis, under a phase-contrast microscope. The nuclear stage was classified as: germinal vesicle (GV), germinal vesicle breakdown (GVBD), metaphase I (M I), metaphase II (M II) or degenerated oocyte, respectively. Oocytes were generally considered to have matured when they reached the M II stage (9).

\subsection{In vitro Fertilization and Culture}

In vitro fertilization was performed based upon the method published by Ushijima et al. (14). Frozen-thawed spermatozoa (Lori Bakhtiari breed) were diluted in TCM 
199 with Earle's salts (Gibco, Grand Island, NY, USA) the $\mathrm{pH}$ was adjusted to 7.8 and then centrifuged at $200 \times \mathrm{g}$ for 2 minutes. Subsequently, the supernatant was removed and the pellet containing the sperm was preincubated for 15 minutes at $38.5^{\circ} \mathrm{C}$ prior to fertilization. Drop of fertilization medium $(90 \mu \mathrm{L})$ which contained in vitro matured COCs $(n=10-20)$ was mixed with $10 \mu \mathrm{L}$ of preincubated spermatozoa. The final concentration of spermatozoa in the fertilization droplets was $1 \times 106$. The fertilization medium comprises of $12 \mathrm{mM} \mathrm{KCl,} 25 \mathrm{mM} \mathrm{NaHCO} 3,90 \mathrm{mM}$ $\mathrm{NaCl}, 0.5 \mathrm{mM} \mathrm{NaH2PO}$, $0.5 \mathrm{mM} \mathrm{MgSO}$, $10 \mathrm{mM}$ sodium lactate, $3 \mathrm{mg} / \mathrm{mL}$ bovine serum albumin (BSA; fatty acid free), $50 \mu \mathrm{g} / \mathrm{mL}$ gentamicin and $5 \mathrm{mM}$ caffeine. Following a period of $12 \mathrm{~h}$ co-incubation of oocytes with spermatozoa, the cumulus investment and the attached spermatozoa were dissociated from the inseminated oocytes by performing mechanical forces (gentle pipetting), and then the fertilized oocytes were transferred to culture medium. Presumptive zygotes were cultured in NCSU-37 supplemented with $4 \mathrm{mg} / \mathrm{ml} \mathrm{BSA}, 0.17 \mathrm{mM}$ sodium pyruvate, $2.73 \mathrm{mM}$ sodium lactate and $50 \mu \mathrm{g} / \mathrm{mL}$ gentamicin. Seventy-two hours after insemination, all cleaved embryos were transferred into a fresh culture medium: NCSU-37 supplemented with $4 \mathrm{mg} / \mathrm{mL}$ BSA, $5.55 \mathrm{mM}$ D-glucose, and $50 \mu \mathrm{g} / \mathrm{mL}$ gentamicin. The cleaved embryos were cultured for seven days to evaluate their ability to develop into morula and blastocyst stages.

Presumptive zygotes were fixed in fixative solution ( $2 \%$ paraformaldehyde $+2 \%$ glutaraldehyde in PBS) and kept at $4^{\circ} \mathrm{C}$ for 24 hours. The fixed presumptive zygotes were subsequently stained with Hoechst $33342(5 \mu \mathrm{g} / \mathrm{mL}$ in PBS) for 10 minutes in the dark at room temperature. After putting a drop of glycerol with 1, 4-diazabicyclo (2.2.2) octane (DABCO) on the siliconised slide, 5-10 zygotes were placed and coverslipped. Pronuclei of presumptive zygotes were identified by epifluorescence microscopy (Leica, DMR) at a magnification $400 \times$ (oil immersion). Zygotes with 2 pronuclei (PN) were considered as being normally fertilized and those with more than 2 PN were considered to be polyspermic (15).

Data are expressed as Mean \pm SEM. After IVF the proportion of oocytes reaching each stage of meiosis, oocytes fertilized and embryos were subjected to arc-sin transformation before analysis of variance (ANOVA). Transformed data were analyzed using ANOVA followed by a post hoc, Fisher's protected least significant difference test (PLSD test) using the Stat view software (Abacus Concepts, Inc. Berkeley, CA). A P $\leq 0.05$ was considered significant difference.

\section{Results}

Effects of different oocyte harvesting methods on the recovery and meiotic resumption rates and oocyte quality are shown in the Tables 1 and 2 . The mean numbers of recovered oocytes using the ORC technique and slicing were significantly higher than the mean numbers of recovered oocytes via puncture and aspiration in both breeding and non-breeding seasons (Table 1). However, the mean numbers of recovered oocytes in breeding season were higher $(\mathrm{P}<0.05)$ than those obtained in non-breeding season, throughout recovery techniques. In addition, the results indicated that in breeding and non-breeding seasons, oocytes class I obtained via aspiration method were significantly $(\mathrm{P}<0.05)$ lower compared with ORC, slicing and puncture. While oocytes class III recovered using aspiration technique were significantly $(P<0.05)$ higher in both breeding and non-breeding seasons compared to the other methods (Table 2).

The proportion of fertilized oocytes that exhibited monospermy was significantly $(\mathrm{P}<0.05)$ lower for those oocytes recovered via aspiration in both breeding (48.2 $\pm 1.6)$ and non-breeding season $(39.4 \pm 1.7)$ than those obtained by the other techniques (Table 3 ). In contrast, the polyspermy rates following IVF for those oocytes recovered using aspiration were higher in both breeding (18.4 $\pm 1.7)$ and non-breeding ( $32.6 \pm 1.3)$ seasons than that obtained by other methods (Table 3). On the other hand, results revealed that in non-breeding season presumptive zygotes that exhibited monospermy were significantly $(\mathrm{P}<0.05)$ lesser compared to those of breeding season (Table 3). Furthermore, the results from this experiment showed that the cleavage and the blastocysts' formation rates were significantly $(\mathrm{P}<0.05)$ affected by harvesting techniques and seasons (Table 4 ).

Table 1. Number of Recovered Oocytes and Metaphase II Rate ${ }^{a}$

\begin{tabular}{lcccccc}
\hline & Breeding Season & & \multicolumn{2}{c}{ Non-Breeding Season } \\
\hline $\begin{array}{l}\text { Recovery } \\
\text { Technique }\end{array}$ & No. of Ovaries & $\begin{array}{c}\text { No. of Recovered } \\
\text { Oocytes }\end{array}$ & $\begin{array}{c}\text { Metaphase II } \\
\text { Rate }\end{array}$ & $\begin{array}{c}\text { No. of Ova- } \\
\text { ries }\end{array}$ & $\begin{array}{c}\text { No. of Recovered } \\
\text { Oocytes }\end{array}$ & $\begin{array}{c}\text { Metaphase II } \\
\text { Rate }\end{array}$ \\
\hline ORC & 100 & $9.8 \pm 0.7^{\mathrm{ad}}$ & $78.3 \pm 2.1^{\mathrm{ad}}(767)$ & 100 & $6.7 \pm 0.9^{\mathrm{ae}}$ & $77.8 \pm 1.2^{\mathrm{ad}}(521)$ \\
Slicing & 100 & $8.6 \pm 0.9^{\mathrm{ad}}$ & $78.8 \pm 1.5^{\mathrm{ad}}(678)$ & 100 & $5.3 \pm 1.3^{\text {ae }}$ & $78.4 \pm 1.0^{\mathrm{ad}}(416)$ \\
Puncture & 100 & $5.8 \pm 1.0^{\mathrm{bd}}$ & $77.4 \pm 2.1^{\mathrm{ad}}(449)$ & 100 & $3.4 \pm 1.1^{\mathrm{be}}$ & $76.7 \pm 2.3^{\mathrm{ad}}(261)$ \\
\hline Aspiration & 100 & $3.3 \pm 1.1^{\mathrm{cd}}$ & $78.2 \pm 1.7^{\mathrm{ad}}(258)$ & 100 & $2.8 \pm 0.7^{\mathrm{ce}}$ & $79.3 \pm 1.8^{\mathrm{ad}}(222)$ \\
\hline
\end{tabular}

a All of the values are presented as (Mean \pm SEM). Different superscripts ( $a$, b, and $c)$ in the same column differ significantly (P $<0.05)$. Different superscripts ( $d$ and $e$ ) in the same row differ significantly $(\mathrm{P}<0.05)$. 
Dadashpour Davachi Netal.

Table 2. Number of Recovered Oocytes and Quality Grades (\%) ${ }^{\mathrm{a}}$

\begin{tabular}{|c|c|c|c|c|c|c|c|}
\hline \multirow[b]{2}{*}{$\begin{array}{l}\text { Recovery } \\
\text { Technique }\end{array}$} & \multicolumn{4}{|c|}{$\begin{array}{c}\text { Breeding Season (No. and \% of Recovered Oocytes of } \\
\text { Each Class) }\end{array}$} & \multicolumn{3}{|c|}{$\begin{array}{c}\text { Non-Breeding Season (No. and \% of Recovered Oocytes } \\
\text { of Each Class) }\end{array}$} \\
\hline & $\begin{array}{l}\text { No. of } \\
\text { Ovaries }\end{array}$ & $\mathbf{I}$ & II & III & $\begin{array}{l}\text { No. of } \\
\text { Ovaries }\end{array}$ & II & III \\
\hline ORC & 100 & $82.0 \pm 1.2$ ad $(803)$ & $9.1 \pm 1.4^{\mathrm{ae}}(89)$ & $9.0 \pm 1.6^{\mathrm{ae}}(88)$ & 100 & $70.0 \pm 1.2^{\text {af }}(469) 16.4 \pm 1.5^{\mathrm{ag}}(110)$ & $13.6 \pm 1.0 \mathrm{ag}(91)$ \\
\hline Slicing & 100 & $80.0 \pm 2.1^{\mathrm{ad}}(688)$ & $11.2 \pm 2.0^{\text {ae }}(96)$ & $8.8 \pm 1.7^{\mathrm{ae}}(76)$ & 100 & $71.0 \pm 1.4^{\text {af }}(376) \quad 17.0 \pm 2.0^{\mathrm{ag}}(89)$ & $12.3 \pm 1.8^{\text {ah }}(65)$ \\
\hline Puncture & 100 & $80.0 \pm 1.5^{\mathrm{ad}}(464)$ & $12.0 \pm 1.8^{\mathrm{ae}}(68)$ & $8.2 \pm 1.5^{\text {af }}(48)$ & 100 & $72.0 \pm 2.0^{\mathrm{ag}}(245) \quad 6.8 \pm 1.3^{\mathrm{bh}}(23)$ & $21.2 \pm 1.5^{\mathrm{bi}}(72)$ \\
\hline Aspiration & 100 & $60.0 \pm 2.1^{b d}(198)$ & $15.2 \pm 1.7^{\text {ae }}(50)$ & $25.0 \pm 1.2^{\mathrm{bf}}(82)$ & 100 & $51.1 \pm 2.1^{\mathrm{bg}}(143) \quad 18.6 \pm 1.9^{\text {aeh }}(52)$ & $30.4 \pm 1.6^{\mathrm{ci}}(85)$ \\
\hline
\end{tabular}

Table 3. Monospermy and Polispermy Rates a

\begin{tabular}{|c|c|c|c|c|c|c|}
\hline \multirow[b]{2}{*}{$\begin{array}{l}\text { Recovery } \\
\text { Technique }\end{array}$} & \multicolumn{3}{|c|}{ Breeding Season (No. and \% of Oocytes fertilized) } & \multicolumn{3}{|c|}{ Non-Breeding Season (No. and \% of Oocytes fertilized) } \\
\hline & $\begin{array}{c}\text { No. of Oocytes } \\
\text { Examined }\end{array}$ & Monospermy & Polyspermy & $\begin{array}{c}\text { No. of Oocytes } \\
\text { Examined }\end{array}$ & Monospermy & Polyspermy \\
\hline ORC & 100 & $58.4 \pm 1.1^{\text {ad }}(64)$ & $11.6 \pm 2.1^{\text {ae }}(13)$ & 100 & $47.1 \pm 2.0^{\text {af }}(47)$ & $20.0 \pm 1.5^{\mathrm{ag}}(20)$ \\
\hline Slicing & 104 & $57.6 \pm 1.0^{\text {ad }}(60)$ & $11.4 \pm 1.5^{\text {ae }}(12)$ & 100 & $48.3 \pm 1.6^{\mathrm{af}}(48)$ & $20.8 \pm 1.5^{\mathrm{ag}}(21)$ \\
\hline Puncture & 100 & $58.3 \pm 1.3^{\text {ad }}(58)$ & $12.3+2.1^{\mathrm{ae}}(12)$ & 110 & $49.4 \pm 2.1^{\text {af }}(54)$ & $21.0 \pm 1.8^{\mathrm{ag}}(23)$ \\
\hline Aspiration & 110 & $48.2 \pm 1.6^{\mathrm{bd}}(53)$ & $18.4 \pm 1.7^{\text {be }}(20)$ & 101 & $39.4 \pm 1.7^{\mathrm{bf}}(40)$ & $32.6 \pm 1.3^{b g}(33)$ \\
\hline
\end{tabular}

a All of the values are presented as (Mean \pm SEM). Different superscripts ( $a, b$ and $c)$ in the same column differ significantly (P $<0.05)$. Different superscripts ( $\mathrm{d}, \mathrm{e}, \mathrm{f}$ and $\mathrm{g})$ in the same row differ significantly $(\mathrm{P}<0.05)$.

Table 4. Cleavage Oocyte and Blastocyst Rates ${ }^{a}$

\begin{tabular}{|c|c|c|c|c|c|c|}
\hline \multirow[b]{2}{*}{$\begin{array}{l}\text { Recovery } \\
\text { Technique }\end{array}$} & \multicolumn{3}{|c|}{ Breeding Season (No. and \% of Oocytes Fertilized) } & \multicolumn{3}{|c|}{ Non-Breeding Season (No. and \% of Oocytes Fertilized) } \\
\hline & $\begin{array}{l}\text { No. of Zygotes } \\
\text { Examined }\end{array}$ & Cleavage (\%) & Blastocyst (\%) & $\begin{array}{l}\text { No. of Zygotes } \\
\text { Examined }\end{array}$ & Cleavage (\%) & Blastocyst (\%) \\
\hline ORC & 320 & $72.4 \pm 1.6^{\mathrm{ad}}(232)$ & $29.2 \pm 1.1^{\text {ae }}(13)$ & 100 & $64.1 \pm 2.0$ af $(199)$ & $20.1 \pm 2.5^{\mathrm{ag}}(62)$ \\
\hline Slicing & 310 & $61.3 \pm 1.2 \mathrm{bd}_{(190)}$ & $20.1 \pm 1.3$ be $(12)$ & 100 & $52.3 \pm 1.3 \mathrm{bf}_{(165)}$ & $11.2 \pm 1.4 \mathrm{bg}(35)$ \\
\hline Puncture & 310 & $62.0 \pm 1.2^{b d}(192)$ & $19.1+1.8^{\text {be }}(12)$ & 110 & $53.0 \pm 1.4 \mathrm{bf}(167)$ & $11.0 \pm 1.9^{b g}(35)$ \\
\hline Aspiration & 315 & $51.4 \pm 1.3^{\mathrm{cd}}(162)$ & $17.8 \pm 1.5^{\text {be }}(20)$ & 101 & $41.3 \pm 1.9^{\mathrm{cf}}(128)$ & $9.2 \pm 1.9^{b g}(29)$ \\
\hline
\end{tabular}

a All of the values are presented as (Mean \pm SEM). Different superscripts (a, b and c) in the same column differ significantly (P $<0.05)$. Different superscripts ( $d, e, f$ and $g)$ in the same row differ significantly $(P<0.05)$.

\section{Discussion}

The results demonstrated that the oocyte recovery technique has a great influence over the number of recovered oocytes, cleavage and blastocyst's development, while no differences were recorded in case of meiotic resumption rate. By using the aspiration and puncture techniques for oocyte recovery from slaughterhouse material, only the visible follicles were used for oocyte retrieving. It seemed that via the ORC and slicing techniques, the follicles embedded deep within the cortex can be utilized for oocyte retrieving procedures (11). Additionally, it can be concluded from the results obtained via the ORC and slicing techniques that the centrifugation force applied in ORC procedure was the only advantages of this new method when compared to slicing technique. Thus, the higher oocyte recovery rate using the ORC technique can be explained.
In the present study in both breeding and non-breeding seasons, the number of oocytes recovered via the ORC technique ( $9.8 \pm 0.7$ and $6.7 \pm 0.9)$, slicing ( $8.6 \pm 0.9$ and $5.3 \pm 1.3$ ), puncture (5.8 \pm 1.0 and $3.4 \pm 1.1)$ and aspiration ( $3.3 \pm 1.1$ and $2.8 \pm 0.7$, respectively for breeding and non-breeding seasons) were significantly higher when compared to the study in which the follicular oocytes were recovered from goat ovaries using three different methods (aspiration, puncture and slicing) (16). Irrespective of recovery technique the highest number of recovered oocytes was obtained in breeding season. This might reflect the optimum level of gonadotropins and steroids in BS. In a study conducted by Shirazi et al. (17), the percentage of recovered oocytes was higher when using the slicing technique, compared to aspiration (52\% vs. 22\%). A study conducted by Morton et al. (12) 
showed that the recovery of oocytes per ovary considered to be viable for the IVM procedure were $3.3 \pm 0.5,3.1$ $\pm 0.3,3.3 \pm 03$ and $3.0 \pm 0.4$ respectively, for the syringe and aspiration technique set at the flow rates of 25,50 and $100 \mathrm{mmHg}$, while the mean number of recovered oocytes were $9.5 \pm 0.4,9.5 \pm 0.4$ and $6.8 \pm 0.3$ respectively, for three different oocyte harvesting methods (puncturing, slicing and aspiration in sheep). Based on the results of Dadashpour Davachi et al. (11) the numbers of oocytes recovered per ovary were $6.8 \pm 0.3,2.3 \pm 0.4,2.3$ \pm 0.2 and $3.8 \pm 0.1$ respectively, for ORC and aspiration (set at flow rates of 10, 15 and $20 \mathrm{~mL} / \mathrm{min}, 20$ g needle). In a study conducted by Cognie et al. (18) the number of recovered oocytes from sheep and goat ovaries during breeding season were one and two oocytes respectively. Furthermore, results from their study revealed no significant differences between numbers of recovered oocytes in breeding and non-breeding seasons.

The results of present study recorded no significant differences in the percentage of those oocytes reaching metaphase II stage that were recovered in breeding and non-breeding seasons (76.7\% $\leq$ MII $\leq 79.3 \%)$. Arav (19) had previously established a new oocyte recovery method in cattle called Transillumination-Aspiration Ovary (TAO) and the results showed that by using TAO the oocyte recovery rate was significantly improved (7.3 oocytes/ovary) while there was no decreases reported on IVM rate (81\%). The results from a study conducted by Kochhar et al. (20) reported an $85.7 \%$ maturation rate for ovine oocytes with $\geq 3$ layers of cumulus cells. Previously, Dadashpour Davachi et al. (9) also reported $77.0 \pm 2.7$, $77.2 \pm 1.9,53.0 \pm 2.1$ and $2.2 \pm 1.1$ maturation rate in ovine oocytes respectively for COCs with $\geq 5,3-4,1-2$ and no cumulus cell layers.

In the present study, the recovery rate of class I oocytes by using the ORC, slicing and puncture were 82, 80 and $80 \%$ respectively. Based on the results of Morton et al. (12) the recovery of class I oocytes, using aspiration technique was $86 \%$. However, Shirazi et al. (17) reported a low recovery rate of 52 and $22 \%$ respectively using slicing and aspiration methods. Rodriguez et al.(21) recorded a low recovery rate of approximately $60 \%$, for post mortem ovine oocyte retrieval. In a study conducted by Pawshe et al. (16) the aspiration, puncturing and slicing were evaluated in goats for oocyte recovery. The results recorded from those mentioned techniques indicated the highest number of good quality and usable oocytes enclosed with compact cumulus cells were obtained per ovary following the slicing, compared to aspiration or puncturing. Dadashpour Davachi et al. (11) reported a recovery rate of $77 \%$ for class I + II + III oocytes using ORC and 90\% when using aspiration technique (set at flow rate of $10 \mathrm{~mL} / \mathrm{min} \mathrm{H} 2 \mathrm{O}$ ). Pierson et al. (22) showed that following gonadotrophin (FSH and eCG) stimulation and laparoscopy ovum pick up (LOPU) in goats the number of recovered oocytes and meiotic resumption rate did not differ significantly between breeding and non-breeding seasons and it might be interpreted as gonadotrophin stimulation which can overcome any inconvenience caused by non-breeding season in IVEP procedure. In this study, results showed that oocytes collected via ORC in breeding and non-breeding seasons were more competent for IVF. Moreover, oocytes obtained via ORC showed a higher percentage of monospermic fertilization. In a study conducted by Shabankareh and Zandi et al. (23) results showed that cleavage and blastocyst rates were 73 and $20 \%$ respectively. The results of the present study in breeding season when using ORC for harvesting oocyte were significantly higher compared to the blastocyst rate reported by Shabankareh and Zandi (23). Various earlier studies have shown that the blastocyst rates were between 22-27\% (12, 24-26). The results of a study conducted by Arav (19) revealed that using TAO lead to 52 and $26 \%$ of cleavage and blastocyst rates respectively. On the other hand, Morton et al. (12) indicated that the proportions of cleaved oocytes were $31,50,47$ and $44 \%$ and the blastocyst rates (as percentage of cleaved oocytes) were 19.5, 54, 44 and 58\% respectively when used two different harvesting oocyte methods (aspiration technique at 25, 50 and $100 \mathrm{~mm} \mathrm{Hg}$ flow rate and syringe, respectively).

Oocyte competence was affected by a harvesting technique applied for oocyte recovery. However, it appeared that seasonal impact on oocyte quality and reproductive performance, even in vitro or in vivo, may compensate for deteriorative effects of recovery technique. The possible explanation for these findings may relate to the critical role of animal physiological status on cumulus cells performance. Previously researchers have indicated that there are several metabolites and growth factors produced in the cumulus cells (27). These micro and macro molecules have a great impact on the oocyte's competence and subsequent embryonic developmental potential. Oocyte harvesting technique would be considered as a first external stressor which oocytes encountered with. Aspiration technique may influence the gap-junctional communication between oocyte and their cumulus investments. Therefore, many useful metabolites for the oocyte and embryo competence which only provided by the cumulus investments cannot reach the oocytes. This may lead to some deterioration in the fertility rate or even in the subsequent embryonic development. While we can propose that other techniques, especially ORC has not influenced the gap-junctions in COCs. On the other hand, different seasons may alter cumulus cells performance from several "known and unknown" mechanisms. We suggest more studies to investigate the integrity of these gap-junctions by applying Lucifer yellow, which can pass through these junctions. It may provide a great indication regard with to the gap-junctions integrity. Also, further studies will be required to elucidate the true mechanisms involved in the seasonal effect on early embryonic development. 


\section{Acknowledgements}

These data were derived from a part of PhD thesis of $\mathrm{Mr}$. Dadashpour Davachi. We appreciate Mrs. Akram Rezaie for her cooperation in last 5 years to handle all the official documents. Also we would like to appreciate Yahoo-Teb Novin corporation staffs for their assistance in this project.

\section{Authors' Contributions}

Study design and manuscript preparation was performed by Navid Dadashpour Davachi. Ahmad Zare Shahneh, Hamid Kohram, and Mahdi Zhandi were participated in proof reading of the manuscript.

\section{Financial Disclosure}

None of the authors of this manuscript have a financial or personal relationship to other people or organizations that could inappropriately influence or be bias in the content of the manuscript.

\section{References}

1. Rosa HJD, Bryant MJ. Seasonality of reproduction in sheep. Small Rumin Res. 2003;48(3):155-71.

2. Wani NA, Wani GM, Khan MZ, Salahudin S. Effect of oocyte harvesting techniques on in vitro maturation and in vitro fertilization in sheep. Small Rumin Res. 2000;36(1):63-7.

3. Wang Z, Yu S, Xu Z. Effects of Collection Methods on Recovery Efficiency, Maturation Rate and Subsequent Embryonic Developmental Competence of Oocytes in Holstein Cow. Asian-Australian JAnim Sci. 2007;20(4):496-500.

4. Harper KM. Bovine blastocyst development after in vitro maturation in a defined medium with epidermal growth factor and low concentrations of gonadotropins. Biol Rep J. 1993;48(2):409-16.

5. Belaisch-Allart JC, Hazout A, Guillet-Rosso F, Glissant M, Testart J, Frydman R. Various techniques for oocyte recovery in an in vitro fertilization and embryo transfer program. J in vitro Fertil Embryo Transfer. 1985;2(2):99-104

6. Carolan C, Monaghan P, Gallagher M, Gordon I. Effect of recovery method on yield of bovine oocytes per ovary and their developmental competence after maturation, fertilization and culture in vitro. Theriogenol J.1994;41(5):1061-8.

7. Bartlewski PM, Vanderpol J, Beard AP, Cook SJ, Rawlings NC. Ovarian antral follicular dynamics and their associations with peripheral concentrations of gonadotropins and ovarian steroids in anoestrous Finnish Landrace ewes. Anim Reprod Sci. 2000;58(34):273-91.

8. Ramsingh L, Sadasivarao K, Muralimohan K. Ovarian Biometrics and Oocyte Grading Percentage of Yield in Local Goats of Andhra Pradesh. Iosr J Pharma. 2013;3(1).

9. Dadashpour Davachi N, Kohram H, Zainoaldini S. Cumulus cell layers as a critical factor in meiotic competence and cumulus expansion of ovine oocytes. Small Rumin Res. 2012;102(1):37-42.
10. Bernardi ML, Flechon JE, Delouis C. Influence of culture system and oxygen tension on the development of ovine zygotes matured and fertilized in vitro. J Reprod Fertil. 1996;106(2):161-7.

11. Dadashpour Davachi N, Zeinoaldini S, Kohram H. A novel ovine oocyte recovery method from slaughterhouse material. Small Rumin Res. 2012;106(2-3):168-72.

12. Morton KM, de Graaf SP, Campbell A, Tomkins LM, Maxwell WM, Evans G. Repeat ovum pick-up and in vitro embryo production from adult ewes with and without FSH treatment. Reprod Domest Anim. 2005;40(5):422-8.

13. Blondin P, Coenen K, Guilbault LA, Sirard MA. In vitro production of bovine embryos: Developmental competence is acquired before maturation. Theriogenol J.1997;47(5):1061-75.

14. Ushijima H, Yamakawa $H$, Nagashima H. Cryopreservation of bovine pre-morula-stage in vitro matured/in vitro fertilized embryos after delipidation and before use in nucleus transfer. Biol Reprod.1999;60(2):534-9.

15. Thys M, Vandaele L, Morrell JM, Mestach J, Van Soom A, Hoogewijs $\mathrm{M}$, et al. In vitro fertilizing capacity of frozen-thawed bull spermatozoa selected by single-layer (glycidoxypropyltrimethoxysilane) silane-coated silica colloidal centrifugation. Reprod Domest Anim. 2009;44(3):390-4.

16. Pawshe $\mathrm{CH}$, Totey SM, Jain SK. A comparison of three methods of recovery of goat oocytes for in vitro maturation and feritilization. Theriogenol J.1994;42(1):117-25.

17. Shirazi A, Shams-Esfandabadi N, Hosseini SM. A comparison of two recovery methods of ovine oocytes for in vitro maturation. Small Rumin Res. 2005;58(3):283-6.

18. Cognie Y. State of the art in sheep-goat embryo transfer. Theriogenol J.1999;51(1):105-16.

19. Arav A. Transillumination increases oocyte recovery from ovaries collected at slaughter. A new technique report. Theriogenol J. 2001;55(7):1561-5.

20. Kochhar HP, Wu B, Morris LH, Buckrell BC, Pollard JW, Basrur PK, et al. Maturation status, protein synthesis and developmental competence of oocytes derived from lambs and ewes. Reprod Domest Anim. 2002;37(1):19-25.

21. Rodriguez C, Anel L, Alvarez M, Anel E, Boixo JC, Chamorro CA, et al. Ovum pick-up in sheep: a comparison between different aspiration devices for optimal oocyte retrieval. Reprod Domest Anim. 2006;41(2):106-13.

22. Pierson J, Wang B, Neveu N, Sneek L, C?t F, Karatzas CN, et al. Reprod Fertil Dev. 2004;16(8):795.

23. Shabankareh HK, Zandi M. Developmental potential of sheep oocytes cultured in different maturation media: effects of epidermal growth factor, insulin-like growth factor I, and cysteamine. Fertil Steril. 2010;94(1):335-40.

24. Cummins JM, Wakayama T, Yanagimachi R. Fate of microinjected spermatid mitochondria in the mouse oocyte and embryo. $Z y$ gote. 1998;6(3):213-22.

25. Im KS, Park KW. Effects of epidermal growth factor on maturation, fertilization and development of bovine follicular oocytes. Theriogenol J. 1995;44(2):209-16.

26. Maalouf WE, Lee JH, Campbell KH. Effects of caffeine, cumulus cell removal and aging on polyspermy and embryo development on in vitro matured and fertilized ovine oocytes. Theriogenology. 2009;71(7):1083-92.

27. Hafez IM, Ansell S, Cullis PR. Tunable pH-sensitive liposomes composed of mixtures of cationic and anionic lipids. Biophys $J$. 2000;79(3):1438-46. 